\title{
Nacimiento y muerte del hombre. Retorno de lo trágico y anuncio del superhombre
}

The Birth and Death of Man. The Return of the Tragic and the Announcement of the Super-Man

Nascimento e morte do homem. Retorno do trágico e anuncio do super-homem

\section{Consuelo Pabón Alvarado*}

Artículo de investigación

Revista Colombiana de Educación, N. 7 72. Primer semestre de 2017, Bogotá, Colombia.

Para citar: Pabón, C. (2017). Nacimiento y muerte del hombre. Retorno de lo trágico y anuncio del superhombre. Revista Colombiana de Educación, (72), 159-176.

Fecha de recepción: 30/08/2016

Fecha de aceptación: 29/11/ 2016

* Doctorado en Filosofía de la Universidad de París VIII. Profesora Universidad Pedagógica Nacional, Bogotá, Colombia. Correo electrónico: casacaballo@hotmail.com 


\section{Resumen}

La tesis que se desarrolla tiene como referentes las obras de Nietzsche, Artaud, Foucault y Deleuze. Construye, desde una propuesta entre teatral y filosófica, una crítica a la idea del Hombre y de las Ciencias Humanas mostrándolas más como ejercicios de poder-saber que como efectivas reivindicaciones de la vida sobre la tierra. Muestra cómo la historia del Hombre, con mayúscula, es reciente (fines del siglo XVIII y comienzos del siglo XIX), y cómo desde Nietzsche esta figura es analizada genealógicamente como portadora de enfermedad y decadencia, hasta llegar al anuncio de la muerte del Hombre, o su superación con la construcción dionisíaca del Superhombre. En el plano sensible, el texto busca, desde tres actos "crueles" que pueden presentarse en un salón de clase, in-corporar problemas filosóficos contemporáneos haciéndolos vívidos a través de personajes conceptuales que fuercen al espectador a pensar y sentir de manera crítica su actualidad.

Palabras clave:

hombre, historia, ciencias humanas, muerte del hombre, superhombre, subjetivación

\section{Keywords:}

man, history, human sciences, death of man, super-man, subjectification

\begin{abstract}
The thesis developed here uses as reference the works by Nietzsche, Artaud, Foucault, and Deleuze. Based on a proposal between theatrical and philosophical, it constructs a critique of the idea of Man and Human Sciences, by presenting them more like exercises of power-knowledge than effective claims of life on earth. It also demonstrates how the history of Man, with a capital letter, is recent (late eighteenth and early nineteenth century), and how, since Nietzsche, this figure has been analyzed genealogically as a bearer of disease and decay, until reaching the announcement of the death of Man, or its overcoming with the Dionysiac construction of the Super-Man. On the sensitive level, the text seeks, from three "cruel" acts that can be presented in a classroom, to in-corporate contemporary philosophical problems by making them vivid through conceptual characters that force the spectator to critically think and feel their present.
\end{abstract}

\section{Resumo}

A tese que se desenvolve a continuação tem como referências as obras de Nietzsche, Artaud, Foucault y Deleuze. Constrói, desde uma proposta entre teatral e filosófica, uma crítica à ideia do Homem e das Ciências Humanas mostrando-as como exercícios de poder-saber mais do que reivindicações efetivas da vida sobre a terra. Mostra como a história do Homem, com maiúscula, é recente (Finais do século XVIII e princípios do século XIX), e como desde Nietzsche essa figura é analisada genealogicamente como portadora de doença e decadência, até chegar ao anuncio da morte do Homem ou sua superação com a construção dionisíaca do Super-homem. No plano sensível, o texto procura desde três atos "cruéis" que podem ser apresentados na sala de aula, incorporar problemas filosóficos contemporâneos fazendo-os vívidos através de personagens conceituais que forcem o espectador a pensar e sentir de forma crítica sua atualidade.

\section{Palavras chave:}

homem, história, ciências humanas, morte do homem, super-homem, subjetivação. 


\section{Introducción}

En este texto mostraremos, desde tres actos, una mirada en la que el Hombre, con mayúscula, será ubicado desde su reciente surgimiento, junto con el nacimiento de la Historia lineal y de las Ciencias Humanas (siglos XVIII y XIX), para Ilegar, con Nietzsche, a la fragmentación de la Historia, y con las guerras del siglo XX, al debilitamiento de los humanismos. Acto seguido, entraremos en la pregunta de Primo Levi: ¿eso es un hombre?, para comprender el sentido de la resistencia ante "la vergüenza de ser un hombre" y la necesidad de construir modos de existencia más allá de lo humano. Luego, en una tercera aproximación, vamos a señalar el problema, que plantea Nietzsche, de la enfermedad del Hombre y el anuncio de su muerte. Tal muerte va acompañada por la afirmación vitalista del Dionisos-Superhombre, como resistencia ante el control y la creciente extinción de la vida en La Tierra, a través de líneas de fuga que construyen modos de existencia más allá de lo humano.

El texto, con argumentos de Foucault, Nietzsche y Deleuze en torno al nacimiento y la muerte del Hombre y la construcción del Superhombre, se presenta bajo la atmósfera del teatro de la crueldad, de Artaud, y propone, críticamente, más preguntas que certezas: ¿Qué derechos tenemos los hombres, los animales y las plantas y los minerales, etc., ante las decisiones del Hombre blanco, patriarcal, capitalista, que pretende controlarlo todo y decidirlo todo desde las nuevas tecnologías, en una desaparición creciente de su "humanidad"? ¿Quién es ese Hombre que no tiene en cuenta la vida de los hombres ni de La Tierra en su conjunto, sino los intereses económicos y tecnológicos que le permiten controlar cada palmo de del planeta? El texto se cierra con el anuncio del Superhombre, o afirmación de la vida, que exige una transmutación de la cultura, al crear modos de existencia que funcionen como líneas de fuga frente al biopoder que se impone y limita la vida planetaria en su conjunto. Como conclusión, propondremos prácticas de vida, ese "hacer de la vida una obra de arte", esas subjetivaciones que serán el escenario desde donde aparecerá la máscara de Dionisos, y, sobrepuesta a ella, la máscara del Superhombre, que danza y canta por encima del Hombre.

\section{Primer acto: la irrupción del Hombre, $y$ el anuncio de su muerte}

Imaginemos un salón de clase donde el profesor y los alumnos presentan una extraña clase de filosofía: en este primer acto, el escenario permite ver y escuchar la irrupción de varios personajes conceptuales: el Hombre, su nacimiento y su muerte, junto con el nacimiento y la muerte de las

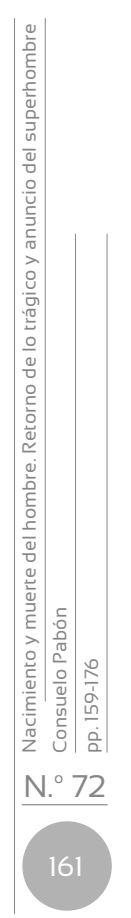


llamadas Ciencias Humanas; aparecen también el nacimiento y la muerte de la Historia. El presentador es una mezcla de corifeo trágico y profesor de filosofía. Él es quien introduce los personajes y establece el tejido explicativo de los actos. Algunos alumnos se convierten en personajes conceptuales; otros mantienen su condición de público afectado. Aparece el profesor de filosofía, quien dice al público, anotando en el tablero:

El HOMBRE es... diferente de los hombres...

Dice, entonces: lo primero que es necesario pensar es la diferencia entre "los hombres" y el Hombre, con mayúscula, y quien, según Foucault, solo aparece con el pensar de la Historia, a finales del siglo XVIII, y se fortalecerá durante el siglo XIX encontrando con Nietzsche el anuncio de su ocaso y su muerte. De ahí que para Foucault (1968), el Hombre sea un enunciado reciente que no cesa de desaparecer. Esto es lo que trata en Las palabras y las cosas: allí nos dice que antes del Hombre había hombres que se inquietaban por lo eterno, lo divino, lo celeste; o bien, se preguntaban por las verdades, o por ellos mismos, por sus modos de vida. Hubo también hombres que se preguntaron por el orden y por metodologías que sirvieran para representarse el mundo y conocerlo científicamente. Pero es con el lluminismo y con el pensar histórico como se construye esa figura universalista del Hombre, figura antropocéntrica, y muchas veces prepotente, que aparece junto con las Ciencias Humanas - es decir, la antropología, la sociología y la psicología-, como saberes-poderes que con sus dispositivos se imponen sobre los hombres controlándolos y metiéndose en los resquicios más íntimos de su existencia.

Mientras el expositor habla, escribe sobre el tablero: LAS PALABRAS Y LAS COSAS de Foucault, escrito en 1966...

Se escucha de pronto la voz de Michel Foucault, voz que sale al aire grabada en una audición radial, llamada La Inquietud del otro:

El hombre es una figura de reciente aparición. Es un prejuicio creer que ha sido la más antigua de nuestras preocupaciones. A pesar de las apariencias, no ha llegado a ser sino muy recientemente la principal inquietud de nuestra civilización. En Grecia la preocupación era la naturaleza, era el cosmos, eran los dioses. En la época clásica, (siglos XVII y XVIII), la preocupación era la verdad, eran las matemáticas, era el orden del mundo y los seres naturales. Pero no era el hombre mismo el que ocupaba el centro de las preocupaciones. El hombre no ha aparecido en ese lugar privilegiado sino muy tardíamente ya en el siglo xix. (Foucault, 1999).

Y, ¿cómo aparece el Hombre? —se pregunta el corifeo—. De pronto, toma un tambor, $y$ toca un ritmo intenso, mientras dice cantando algunos apartes de Las palabras y las cosas, de Foucault: el Hombre se convierte, gracias a Kant, en un a priori histórico (empírico y trascendental) que 
permite, sin duda, la aparición de las Ciencias Humanas: la antropología, la sociología y la psicología fueron las que comenzaron la ardua tarea de encontrar el núcleo de lo humano...Y para ello se fundamentaron en la Historia y en lo científico, en las nuevas empiricidades, como la biología, la economía política, la filología y la lingüística...

Aparece, entonces, un fragmento del documental Foucault por sí mismo en la pantalla del televisor, y vemos, en blanco y negro, la imagen de Foucault diciendo:

Este hombre completamente nuevo inventado a finales del siglo XVIII también dio lugar a todo ese humanismo del cual el marxismo y el existencialismo son actualmente los testimonios más visibles. Pero creo que paradójicamente el desarrollo de las ciencias humanas ha llevado ahora más a una desaparición del hombre que a una apoteosis del hombre... (Calderón, 2003).

Desaparece la imagen de Foucault y continúa el corifeo diciendo, mientras toca lentamente el tambor: Foucault muestra cómo el Hombre desde Kant se convierte en objeto de estudio, en objeto de ciencia, en un objeto más para el pensamiento crítico de la filosofía trascendental. En efecto, cuando en sus estudios sobre Las palabras y las cosas, traduce al francés los cursos de Kant sobre la antropología y publica sus traducciones en Una lectura de Kant. Introducción a la antropología en sentido pragmático; entonces, dice lo siguiente:

Kant en el prefacio a la Antropología trata de describir no lo que el Hombre es, sino lo que puede hacer de sí mismo; (...) luego en 1789, modifica el término y ya no buscará saber "cómo se puede utilizar al hombre", sino lo que "se puede y se debe esperar de él", lo que el hombre puede y debe hacer de sí mismo. Es decir, que el uso es arrancado del nivel de la actualidad técnica y colocado en un doble sistema: de obligación afirmada con respecto a sí, de distancia respetada en relación con los otros. Es situado en el texto de una libertad que se postula a la vez como singular y universal." (...) "Al tratar al Hombre como ser que actúa libremente, la Antropología despeja toda una zona de 'libre intercambio', en la que el hombre hace circular sus libertades como de mano en mano, vinculándose así a los otros por medio de un comercio sordo e ininterrumpido, que le procura una residencia en toda la superficie de la tierra. Ciudadano del mundo. (Foucault, 2009, pp. 58-61, y 68).

Pero en realidad — dice el corifeo—, el libre intercambio solo lo posee el Hombre, con mayúscula: solo él puede ser el ciudadano del mundo, porque puede asumir su libertad desde un punto de vista moral. Los otros hombres, que no pueden tener esa libertad moral, entran en un comercio distinto: son cosas, objetos o animales. Desde ahí, desde esa libertad moral 
que se adjudica el Hombre quitándosela a los demás hombres, establecerá "libremente" un comercio con ellos, a quienes no necesariamente tratará como a sus iguales: por ejemplo, en la Antropología, Kant dice que la mujer es un animal doméstico, es una cosa poseída. Dice el texto sobre Kant "Acerca del derecho personal de modalidad real que se dividía en tres dominios de acuerdo con las tres formas esenciales de la adquisición: el hombre adquiere una mujer, la pareja adquiere hijos y la familia adquiere criados". De la misma manera, con los sirvientes también hay jurídicamente, como en el caso del matrimonio, una relación de posesión. “Tal es la paradoja de la relación del hombre con la mujer descrita en la Antropología, en el estado de la naturaleza la mujer no es sino Haustier (animal doméstico)" (Foucault, 2009, p. 60). Y en los Escritos y cartas sobre el cuerpo y el espíritu, Kant dirá también que otras culturas, como los patagones, no han salido nunca de la animalidad, así como los niños, frente a los cuales no se pueden hacer juicios morales ni imputarles faltas, porque no han logrado, como el Hombre, juzgarse a sí mismos, ni, por lo tanto, ser responsables de sus actos (Kant, 2007).

Sigue retumbando el tambor... El corifeo hace entrar a la Historia, un personaje grandote, que casi no cabe en la silla, sino que se expande longitudinalmente: ella parece, más bien, una línea-boa que atraviesa el espacio. Es la línea que imaginó Kant cuando hablaba del tiempo como sentido interno en la Estética Trascendental, y respecto a lo cual dice:

Debido precisamente al hecho de que esta intuición interna no nos ofrece figura alguna, intentamos enjugar tal déficit por medio de analogías y nos representamos la secuencia temporal acudiendo a una línea que progresa hacia el infinito, una línea en la que la multiplicidad forma una serie unidimensional. (Kant, 1978, p. 77).

Además, Kant resuelve con esa línea del tiempo lo que Descartes pudo resolver con Dios: en Kant es el tiempo, la línea del tiempo, lo que vincula el pienso con la existencia: la forma como el yo soy es determinado por el yo pienso es a través del tiempo; es el tiempo lo que establece un lazo memorioso que identifica el pienso con el existo. Como resulta evidente, dicha percepción temporal está íntimamente ligada a la subjetividad moderna. Toda la multiplicidad de acontecimientos que le suceden a un sujeto es capturada por la línea memoriosa del tiempo que lo identifica consigo mismo, y que une acontecimiento tras acontecimiento en una línea unidimensional que permite decir: "y todo esto soy yo". Es la línea que reúne de manera progresiva el presente, el pasado y el futuro, y que traza los proyectos humanistas del Siglo de las Luces y la Revolución francesa: bienestar, progreso, fraternidad, igualdad para toda la Humanidad. Línea que Kant imagina, pero que será desplegada, en realidad, durante los siglos XIX y XX por los positivistas, los evolucionistas, los marxistas, etc. 
Línea que fundó el proyecto humanista trazando un futuro de progreso ineluctable para toda la Humanidad... algo que no se cumplió.

Y Foucault explica en Las palabras y las cosas que sobre la formación histórica del siglo XIX aparecen nuevos saberes que se preguntan más por las fuerzas de la tierra y por el origen que por el Orden representativo clásico. Se trata del trabajo (economía política), de la vida (biología) y del lenguaje (lingüística, filología). Las Ciencias Humanas ocupan, pues, esta distancia que separa (no sin unirlas) la biología, la economía y la filología de eso que les da posibilidad en el ser mismo del hombre: el hombre como ser vivo, el hombre como ser de lenguaje y el hombre como fuerza de trabajo (Foucault, 1968). Y es allí donde se produce un corte con el pensar de la representación y se pasa a historizar: al comienzo se asumió la historia con gran ímpetu, todo se historizó: las ciencias, la educación, las artes, la filosofía, etc. Y sin embargo, ¿cuántas historias no se silenciaron y se oscurecieron, mientras que otras se resaltaron y se difundieron? ¿Quién hace la historia si no el vencedor, el Hombre con mayúscula, el que tiene la libertad moral para juzgar a los otros, el vencedor de hombres, mujeres, niños y de otros seres de la naturaleza? En últimas, ¿esa construcción del humanismo no se realiza para llenar el vacío en el que quedamos a partir de la muerte de Dios y a partir de la conciencia sobre la finitud?

En el espacio entran ahora en escena las Ciencias Humanas: la antropología, la sociología y la psicología. La Historia abre su boca de boa gigantesca y las devora. Ellas se adentran en sus anillos; van al pasado, al presente y al futuro, los recorren, los estudian, buscando "lo otro" dentro de ese cuerpo unidimensional que siempre las conduce a "lo mismo". Dice Foucault en Las palabras y las cosas, a propósito de la relación entre la Historia y las Ciencias Humanas:

En todo caso, esta disposición de la Historia en el espacio epistemológico tiene una gran importancia para su relación con las ciencias humanas. Puesto que el hombre histórico es el hombre vivo, que trabaja y habla, todo contenido de la Historia sea cual fuere depende de la psicología, de la sociología o de las ciencias del lenguaje. Pero, a la inversa, puesto que el ser humano se ha convertido en histórico de un cabo a otro, ninguno de los contenidos analizados por las ciencias humanas puede permanecer estable en sí mismo ni escapar al movimiento de la Historia. Esto se debe a dos razones: porque la psicología, la sociología, la filosofía, aun cuando se las aplica a objetos — es decir, a hombres — que les son contemporáneos, no consideran, jamás sino recortes sincrónicos en el interior de una historicidad que los constituye y los atraviesa; porque las formas tomadas sucesivamente por las ciencias humanas, la elección que hacen de su objeto, los métodos que le aplican son dados por la Historia, sostenidos sin cesar por ella y modificados a su gusto. 
Así, pues, la Historia forma, respecto a las Ciencias Humanas, un medio de acogida que es, a la vez, privilegiado y peligroso. Da a cada ciencia del hombre un trasfondo que la establece, que le fija un suelo y como una patria: determina la playa cultural —el episodio cronológico, la inserción geográfica - en la que puede reconocerse su validez a este saber, pero las discierne de una frontera que las limita y que arruina desde el principio su pretensión de tener validez en el elemento de la universalidad. Revela, de esta manera, que si el Hombre -incluso, antes de saberlo— ha estado sometido siempre a determinaciones que pueden manifestar la psicología, la sociología y el análisis de las lenguas, no es, sin embargo, el objeto intemporal de un saber que - cuando menos, en el nivel de sus derechos- carecería él mismo de edad. Aun si se evita toda referencia a la historia, las Ciencias Humanas (y bajo ese título puede ponerse la Historia entre ellas) no hacen nunca otra cosa que poner un episodio cultural en relación con otro (ese al que se aplican como su objeto y ese en el que se enraízan en cuanto a su existencia, su modo de ser, sus métodos y sus conceptos); y si ellas se aplican a su propia sincronía, relacionan consigo mismo el episodio cultural del que han surgido; tanto, que el Hombre no aparece nunca en su positividad sin que esta se vea de inmediato limitada por lo ilimitado de la Historia... (Foucault, 1968, pp. 359-360).

\section{Sin embargo, como dice Edgar Garavito en sus Escritos escogidos,}

(...) las ciencias humanas aparecen como formaciones de saber y ejercicios de poder que desde fines del siglo xvIII hasta mediados del siglo xx trataron de buscar la armonía entre la dimensión de lo mismo y la dimensión de lo otro. Así, son ciencias humanas la antropología (estudio del otro como etnia), la sociología (estudio del otro como clase), la psicología (estudio del otro como ello). En todas estas prácticas el otro no es el afuera porque el otro es en todos los casos incorporado en la circulación de la significación (...) Podemos constatar por ahora que hubo en las ciencias humanas una clara dimensión política: la antropología luchó por preservar la diferencia étnica y cultural de los pueblos colonizados, al tiempo que era utilizada como instrumento de poder para ejercer una más clara dominación racial y cultural. La sociología promovió las luchas contra la explotación y la alienación en el trabajo, al tiempo que se convirtió en arma para garantizar la autorregulación de un sistema económico que provocaba los desequilibrios sociales. Y la psicología luchó desde su constitución, a comienzos del siglo xIx por destituir los aparatos clásicos de tortura contra los alienados, buscando al mismo tiempo que fuera el propio alienado quien ejerciera la sujeción de su cuerpo y sus pasiones. De esta manera las Ilamadas ciencias humanas no pueden ser separadas de un humanismo político que se planteó a la vez como modelo de dominación e instancia de redención. (1999, pp. 121-122). 
Habría que preguntarse ahora si esas ciencias humanas no han servido sino para ayudar a conocer mejor los comportamientos de los hombres, para, así mismo, poderlos controlar y dirigir mejor. Por ejemplo, en el caso de los psicólogos que manejaron dispositivos del saber-poder en los campos de concentración y sometieron a los hombres a experiencias psíquicas límite para averiguar sobre sus miedos y sus reacciones, y así saber hasta dónde llegaban a asimilar lo insoportable. De ahí que cabría cuestionarse si en la actualidad las Ciencias Humanas siguen contribuyendo, junto con la informática, a la normatización de la sociedad, a su conducción, su control y su sujeción. Es en ese sentido en el cual Foucault plantea que nuestro nuevo oscurantismo está encarnado en los humanismos y anuncia la desaparición de ese Hombre que surgió como una gran escultura realizada por el romanticismo, y que no cesa de ser agrietada por las olas del mar:

\begin{abstract}
El hombre es una invención cuya fecha reciente muestra con toda facilidad la arqueología de nuestro pensamiento. Y quizá también su próximo fin. Si esas disposiciones desaparecieran tal como aparecieron, si, por cualquier acontecimiento cuya posibilidad podemos cuando mucho presentir, pero cuya forma y promesa no conocemos por ahora, oscilarán, como lo hizo, a fines del siglo XVIII el suelo del pensamiento clásico, entonces podría apostarse a que el hombre se borraría, como en los límites del mar un rostro de arena. (Foucault, 1968, p. 375).
\end{abstract}

Como escena final de este primer acto, aparece Nietzsche vestido de Zaratustra y anunciando la muerte del Hombre, su ocaso y la transmutación de la cultura a través de la figura del Superhombre...Con sus dientes, con sus martillazos, rompe la linealidad de la historia e introduce la genealogía, el instante, las múltiples irrupciones de los acontecimientos. La serpiente histórica se rompe, sus anillos se fragmentan y caminan múltiples por el piso y rodeando a los espectadores, mientras que las Ilamadas Ciencias Humanas se desdibujan sobre la tierra, y dejan muchas veces de ser "humanas" para convertirse en instrumentos de tipo económico y social que permitan una mejor conducción de los hombres...

\title{
Segundo acto: fábula sobre la desaparición del Hombre
}

El corifeo hace entrar y salir diversas voces de un coro circular que dice fragmentariamente:

1. En Consideraciones intempestivas, Nietzsche nos presenta una fábula: "En algún apartado rincón del universo centelleante, desparramado en innumerables sistemas solares, hubo una vez un astro 
en el que animales inteligentes inventaron el conocimiento. Fue el minuto más altanero y falaz de la 'Historia Universal': pero, a fin de cuentas, sólo un minuto. Tras breves respiraciones de la naturaleza, el astro se heló y los animales inteligentes hubieron de perecer"... "Hubo eternidades en las que el hombre no existía; cuando de nuevo se acabe todo para él no habrá sucedido nada, puesto que para ese intelecto no hay ninguna misión ulterior que conduzca más allá de la vida humana". (2002, p. 3)

2. El Hombre, quien se creyó el centro del Universo, fue tan soberbio que no pudo sino creer que todos los otros seres de la naturaleza debían girar en torno a él. Su gran importancia y sus ilusiones lo destruyeron... Y las moscas seguirán volando sin enterarse siquiera de lo "importante" que fue el Hombre, y, tal vez, La Tierra resplandecerá y los hombres, los animales y las plantas volverán a crecer cuando se extingan incluso nuestro gran conocimiento tecnológico y nuestra gran empresa capitalista. Cuando ese Hombre afirme su ocaso, como afirmación de la vida y se funda en el Uno primordial dionisíaco, cuando aprenda a respetar a La Tierra y a vivir en continuidad con ella, podrá, entonces, hacer posible otra existencia y podrá danzar por los aires, volando... "Zaratustra el bailarín, Zaratustra el ligero, el que hace señas con las alas, uno dispuesto a volar, que hace señas a todos los pájaros, preparado y listo, bienaventurado en su ligereza" (Nietzsche, 1981, pp. 392-393).

3. (Aparecen imágenes de vuelos chamánicos, extraídas del Museo del Oro de Bogotá, y se escuchan voces que cantan Ícaros chamánicos.)

4. Continúa el coro: En otras épocas y territorios, los hombres se transformaban en otros seres de la naturaleza para comprender, curar y conocer mejor los misterios del Universo; vivían en continuidad con la naturaleza, hacían parte de ella; este era el principio del dionisismo. En Suramérica, por ejemplo, había la gente tigre, la gente pájaro o la gente anaconda: hombres y mujeres de conocimiento que se relacionaron con el mundo desde los principios de la continuidad y la transmutación. Pero cuando se construyó lo que Ilamamos la Cultura Occidental, los hombres se inventaron la discontinuidad a través de la razón, la representación, la verdad; y al buscar el ser, y no el devenir, se alejaron de la naturaleza suponiendo que debían distanciarse de ella para conocerla mejor y someterla a los intereses humanos. De ahí que los hombres ya no pudieron volar, sino que se convirtieron, como decía Platón, en bípedos sin plumas, o, como diría Aristóteles, en animales racionales. Luego, en la Modernidad, los hombres se inventaron al 
Hombre, con mayúscula, como centro del Universo, que se sentía superior a los otros hombres, a quienes, sin dudarlo, esclavizó, explotó y sujetó de diversas maneras a lo largo de la historia, y nos hizo a los hombres, hasta hoy, los hijos de su guerra.

5. Cantan mujeres y niños del coro: Guerra del Hombre contra los hombres, guerra del Hombre contra La Tierra, guerra por apropiarse de todas las riquezas de la naturaleza y utilizarlas según su capricho. Esto ha implicado una negación, no solo de la vida de los otros hombres, a quienes sojuzgó tantas veces el Hombre, sin reparo alguno... hasta llegar a la Vergüenza de ser un hombre, que es lo que ahora sentimos con Primo Levi ante las masacres contemporáneas. Luego de pasar por los campos de concentración, por los genocidios y las guerras nucleares, ahora nos preguntamos si esto que somos es un Hombre y quién es un Hombre. En los campos de concentración, el hombre para el Hombre se convirtió en objeto-basura que se debía exterminar productivamente, sacarle al máximo su utilidad, para luego cremarlo y reducirlo a cenizas. Millones de "hombres basura" fueron exterminados en nombre del Hombre blanco, limpio, ario...

6. Dicen las voces de Deleuze y Guattari: "Lo que Primo Levi describe es un sentimiento 'compuesto': vergüenza de que hombres hayan podido hacer aquello, vergüenza de que no hayamos podido impedirlo, vergüenza de haber sobrevivido a ello, vergüenza de haber sido envilecido o disminuido" (1993, p. 108). Y nos dice Deleuze en Crítica y Clínica:

El devenir no funciona en el otro sentido, y no se deviene Hombre, en tanto que el hombre se presenta como una forma de expresión dominante que pretende imponerse a cualquier materia, mientras que mujer, animal o molécula contienen siempre un componente de fuga que se sustrae a su propia formalización. La vergüenza de ser un hombre, ¿hay acaso alguna razón mejor para escribir? (1996, p. 5).

Dice el corifeo: Primo Levi encuentra dos términos para designar esa cruda realidad del "animal inteligente" que somos: los salvados y los hundidos. Ante la lucha animal por la sobrevivencia, ante ese límite al que fueron sometidos millones de hombres en los campos de concentración, cuando cada cuerpo humano está solo con su potencia de vida, tendrá que manifestarse de manera desnuda en lo que puede y en lo que no puede, como un animal instintivo.

Me parece digno de atención este hecho: queda claro que hay entre los hombres dos categorías particularmente bien distintas: los salvados 
y los hundidos (...) Esta división es mucho menos evidente en la vida común; en esta no sucede con frecuencia que un hombre se pierda, porque normalmente el hombre no está solo y, en sus altibajos, está unido al destino de sus vecinos, por más que es excepcional que alguien crezca en poder sin límites o descienda continuamente de derrota en derrota hasta la ruina (...) Pero en Lager, Auschwitz , sucede de otra manera: aquí la lucha por la supervivencia no tiene remisión, porque cada uno está desesperadamente, forzosamente solo (...) En la historia y en la vida, parece a veces discernirse una ley feroz que reza: "A quien tiene, le será dado; a quien no tiene le será quitado". En el Lager, donde el hombre está solo y la lucha por la vida se reduce a su mecanismo primordial, esta ley inicua está abiertamente en vigor, es reconocida por todos. Con los adaptados, con los individuos fuertes y astutos, los mismos jefes mantienen con gusto relaciones, a veces casi de camaradas, porque tal vez esperan obtener más tarde una utilidad. Pero a los hombres que se desmoronan, no vale la pena dirigirles la palabra, porque ya se sabe que se lamentarán y contarán lo que comían en su casa (...) Y, finalmente, se sabe que están aquí de paso y que dentro de unas semanas no quedará de ellos más que un puñado de cenizas en cualquier campo lejano y, en un registro, un número de matrícula vencido (...) Si los hundidos no tienen historia, y una sola y ancha es la vía de la perdición, las vías de la salvación son, en cambio muchas, ásperas e impensadas. (Levi, 2011, pp. 118 y 119).

Concluye el coro: Los salvados y los hundidos han estado presentes en todas las historias humanas. La historia misma ha sido escrita, generalmente, por los salvados, por los vencedores; a las víctimas, a los perdidos, les han correspondido el silencio y el olvido. Por eso, resulta necesaria una historia molecular, genealógica, de muchos comienzos, en la que se extraigan del olvido memorias ancestrales que cuenten a su manera las historias singulares y construyan un tejido de memoria colectiva horizontal, polifónica, donde todos los relatos sean importantes... ¿ Se trata de argumentar desde los viejos humanismos la necesidad de volver al Hombre? ¿O se trata, más bien, de celebrar que su rostro de arena se descomponga y se desmorone ante las olas del mar, y que solamente queden los hombres, quienes, al igual que las aves, los tigres y los delfines, solo quieren vivir? Vivir sin categorías que dividan los animales inteligentes de los animales no inteligentes, vivir sin antropocentrismos, ni etnocentrismos, deponiendo esa antigua soberbia que nos Ilevaba a creernos el centro del universo.... Tal vez, es ese vitalismo no humanista el que necesitamos para evitar que La Tierra se destruya, se hiele, y evitar que no solo los hombres, sino todos los seres vivos, desaparezcamos de este astro extraordinario que es La Tierra... 


\section{Tercer acto: retorno de la tragedia y anuncio del Superhombre}

En este acto hay tres personajes: el corifeo, Nietzsche — ciego y vidente- y Deleuze — soplando tabaco-. Mientras la atmósfera se llena de humo, tenuemente aparecen imágenes en una pantalla, y que muestran las guerras más duras que estamos viviendo y los actos de resistencia que se desprenden de ellas. Con los soplos de tabaco, esas imágenes se diluyen, se borran en el espacio, hasta adquirir intensidades fantasmales.

Aparece Nietzsche vidente diciendo:

Yo prometo una edad trágica: el arte supremo en el decir sí a la vida, la tragedia volverá a nacer cuando la humanidad tenga detrás de sí la conciencia de las guerras más duras, pero más necesarias, sin sufrir por ello. (1984, p. 71).

Dice el corifeo: Podemos decir que con esta promesa, Nietzsche está inventando el vitalismo como respuesta al bio-poder, o control sobre la vida. El vitalismo, o afirmación de la vida, es lo que se resiste al bio-poder inventado por el Hombre. En La genealogía de la moral, al estudiar los orígenes mismos de la enfermedad que ha conducido a nuestra cultura hacia el nihilismo extremo, Nietzsche nos muestra cómo la enfermedad humana nace, precisamente, de la desarmonía, del odio y del miedo sistemático del Hombre hacia su propio cuerpo; la enfermedad es el resultado mismo de la negación del cuerpo, y, al mismo tiempo, es el motor que ha hecho posible, desde Sócrates, la construcción de nuestra Cultura Occidental. De ahí que con el resentimiento, la mala conciencia y el ideal ascético se haya producido poco a poco el fortalecimiento de la enfermedad, pues al cohibir los instintos, al no dejarlos liberarse hacia el exterior, al hacerlos volverse hacia dentro, se hace posible el nacimiento de la interiorización, y, por ello mismo, del concepto transmundano de alma. Es en este sentido en el que el alma ha sido tomada moralmente como enemiga del cuerpo, como lo trascendente en el hombre, como lo que debe ser liberado de la confusión, de la pesadez y de la corrupción de lo terrenal, para encontrar salvación en la otra vida.

Vuelve a decir el Nietzsche vidente:

Enfermos y moribundos eran los que despreciaron el cuerpo y la tierra y los que inventaron las cosas celestes y las gotas de sangre redentora: ipero incluso estos dulces y sombríos venenos los tomaron del cuerpo y de la tierra! De su miseria querían escapar, y las estrellas les parecían demasiado lejanas. Entonces suspiraron: “ $\mathrm{OOh}$, si hubiese caminos celestes para deslizarse furtivamente en otro ser y en otra felicidad!"-ientonces se inventaron sus caminos furtivos y sus pequeños brebajes de sangre! 
Entonces estos ingratos se imaginaron estar sustraídos a su cuerpo y a esta tierra. Sin embargo, ¿a quién debían las convulsiones y delicias de su éxtasis? A su cuerpo y a esta tierra. (Nietzsche, 1981, p. 58).

Sigue el corifeo, dirigiéndose a Deleuze, e invocando su libro Nietzsche y la Filosofía: El cuerpo humano se va enfermando poco a poco cuando las fuerzas activas que lo constituían se ven limitadas en su expresión, primero por las fuerzas reactivas, y luego, por las fuerzas que invocan la nada: primero, no puede exteriorizar su valor, su potencia de creación y de transformación, porque su fuerza ha sido limitada, y sus instintos, negados: con la inversión de valores, el fuerte es quien interioriza, y el débil, quien exterioriza; pero incluso la interiorización, el sufrimiento y la autocrueldad son luego rechazados a favor de la comodidad: ese es el último hombre, el pulgón que navega en la nada, y de ella se alimenta y vive mucho tiempo...

Entonces dice Deleuze:

no hay que decir que la fuerza activa se convierte en reactiva porque triunfan las fuerzas reactivas; al contrario, las fuerzas reactivas triunfan porque, al separar la fuerza activa de lo que esta puede, la abandonan a la voluntad de nada, como a un devenir reactivo más profundo que ellas mismas. Por eso las figuras del triunfo de las fuerzas reactivas (resentimiento, mala conciencia, ideal ascético) son en primer lugar, las fuerzas del nihilismo. (2005a, p. 9).

En este sentido, ¿qué puede un cuerpo marcado por el nihilismo? Puede la nada. Por ello, nuestros cuerpos están marcados hoy, aquí y ahora por fuerzas que precipitan la nada. Es el cuerpo del agotado, del anestesiado, del apático que se extingue pasivamente. Es el último de los hombres, quien, por más que tenga la guerra encima, parece como si no la sintiera. Ya en este punto del nihilismo extremo, la voluntad de verdad ha cedido paso a la nada como voluntad. Todas esas metas que se había trazado el hombre moderno en busca de la verdad dejan de tener importancia: ya nadie se muere por la verdad. Ahora lo que importa es la felicidad, el bienestar, la comodidad del último hombre, ese hombre indestructible, el hombre que más tiempo vive, "el último hombre", ese hombre que aún no ha aprendido a bailar por encima de sí mismo, que no ha aprendido a reírse de sí mismo, que no ha aprendido a despreciar su propia reactividad. Sin embargo, hay otro tipo de hombre superior; Nietzsche lo Ilama el "hombre que quiere perecer", el hombre del gran desprecio que precipita su ocaso: cuerpo, marcado por la voluntad de nada, es, gran paradoja, un cuerpo terriblemente poderoso, porque puede autodestruir su propia negatividad. Potencialmente, es el cuerpo Ilamado a hacer la selección, no a convertir la reacción en acción humana, sino a transmutarse, a ir más allá de lo humano; al precipitar la destrucción activa, 
al sobrepasar lo humano, es como vence el nihilismo y hace posible el $S \hat{~}$ dionisiaco. En la transmutación, en efecto, ya no se trata de una simple sustitución, sino de una conversión que consiste en pasar por el "último hombre", pero yendo más allá: es ahí donde el nihilismo encuentra su fin: en el hombre que quiere perecer, que quiere ser superado (Deleuze, 2005a). Cuando la transmutación se produce, la negatividad se niega a ella misma y el eterno retorno se afirma no como retorno de lo mismo, sino como retorno de lo diferente. La crueldad en la filosofía dionisíaca estaría en la afirmación del placer y el dolor que experimenta el cuerpo del Hombre que quiere perecer para alcanzar la plenitud de la vida. Es la experiencia de aniquilamiento de todas las fuerzas reactivas que no lo dejan vivir. Ese es su gran acto creativo: construir la casa para que viva el Superhombre sacrificando todas las fuerzas reactivas, destruyendo todo lo que presenta caracteres degenerados y parasitarios. La enfermedad, como fuerza reactiva, separa al cuerpo de lo que puede. Pero a un mismo tiempo, revela un nuevo poder del cuerpo: se encuentra la salud desde la enfermedad. Se trata de un poder "peligroso" e "interesante" que nos aporta nuevas afecciones, nos enseña nuevas formas de vivir y de ser afectado. "En el devenir reactivo de las fuerzas hay algo admirable, admirable y peligroso. No solo el hombre enfermo, incluso el hombre religioso presenta este doble aspecto: por una parte, hombre reactivo; por otra, hombre de un nuevo poder" (Deleuze, 2005a, p. 201). Si lo reactivo implica el triunfo de la debilidad, el nuevo poder precipita la destrucción de los débiles, su autodestrucción. Continúa Deleuze:

La negación activa, la destrucción activa, es el estado de los espíritus fuertes que destruyen lo que hay de reactivo en ellos, sometiéndolo a la prueba del eterno retorno, y sometiéndose ellos mismos a esta prueba, sin perjuicio de querer su ocaso...esta es la única forma en que las fuerzas reactivas devienen activas. Y más aún: he aquí que la negación al hacerse negación de las propias fuerzas reactivas, no es solamente activa sino que está como transmutada. Expresa la afirmación, expresa el devenir activo como poder de afirmar. (2005a, p. 96).

De ahí la extraordinaria alegría que experimenta un cuerpo al autoaniquilar su pasividad y su nada. La crueldad riente, crueldad dionisíaca, irrumpe cuando el cuerpo, al negar la reactividad que lo determina, al expulsar la enfermedad, va ampliando su poder de afección y conquistando una vida plenificada: poco a poco, va abandonando la enfermedad y cincelando en su cuerpo la más extraordinaria obra de arte: la creación se afirma como nueva salud. Se impone aquí una nueva ética: la ética del Eterno Retorno, ética selectiva en la cual el querer va más allá del yo, más allá de la voluntad individual, querer impersonal que es puesto a prueba por el retorno, y suprime, entonces, toda mediocridad en los actos: cada acto que se realiza 
es una singularidad que merece ser repetida una y mil veces para toda la eternidad. Y termina Deleuze:

en este sentido, el eterno retorno es el instrumento y la expresión de la voluntad de potencia: eleva todas las cosas a su forma superior, es decir, a la enésima potencia. Esta selección creadora no se desarrolla únicamente en el pensamiento del eterno retorno. Se realiza en el ser, el ser es selectivo, es elección. ¿Cómo aceptar que el eterno retorno haga que todo vuelva y que vuelva a ser lo mismo, cuando elimina todo aquello que no pasa la prueba, no solamente el 'querer a medias' en el pensamiento sino el 'poder a medias' en el ser? (2005a, p. 101).

El último hombre no retornará, nada de lo que rechaza el eterno retorno puede volver. Si se quiere mantener la concepción del eterno retorno como una rueda, haría falta dotarla de un movimiento centrífugo, mediante el cual expulsa todo lo que es demasiado débil, demasiado moderado para soportar la prueba. Lo que el eterno retorno produce y hace retornar como corresponde a la voluntad de poder es el Superhombre, definido como "la forma superior de todo cuanto es" (Deleuze, 2005b, p. 164). El retorno de lo dionisiaco en la obra final de Nietzsche es una afirmación del círculo del Eterno Retorno: Dionisos retorna desde la diferencia. La tragedia vuelve a nacer, pues ahora tenemos que enfrentar las guerras más duras y más necesarias, por la vida. La gran pesadez, la gran enfermedad del hombre superior, debe ser transmutada. El retorno del pensamiento de la embriaguez se impone como la última iluminación de Nietzsche. Los ditirambos de Dionisos, o canciones de Zaratustra, son, a la vez, poesía, canto, danza y filosofía; textos embriagados que destruyen las formas tradicionales de transmitir el pensamiento filosófico y desde el cuerpo, desde lo sensible, embriaguez visual y sonora; construyen nuevas maneras de sentir y de pensar, nuevas subjetivaciones por fuera del yo y el tú, todo un arte de la existencia que es indispensable construir como línea de fuga; todo "un arte del estilo" fundado en signos y señales, en visiones y ritmos. Más allá... solo está el silencio. Los ditirambos dionisiacos son signos y señales pronunciados por la boca delirante del profeta.

El espacio que Nietzsche describe como el alma de Zaratustra, es decir, el espacio dionisiaco, constituye el escenario del drama que tiene como único actor a Nietzsche. Los signos son sus máscaras, los gestos de la mímica son alusiones y el delirio su lenguaje lúdico y desafiante. (Gutiérrez, 2005, p. 18).

Y Nietzsche-Zaratustra canta:

Esta corona del que ríe, esta corona de rosas: yo mismo me he puesto sobre mi cabeza esta corona, yo mismo he santificado mis risas... Zaratustra el bailarín, Zaratustra el ligero, el que hace señas con las alas, 
uno dispuesto a volar, haciendo señas a todos los pájaros, preparado y listo, bienaventurado en su ligereza: -Zaratustra el que dice verdad, Zaratustra el que ríe verdad, no un impaciente, no un incondicional, sí uno que ama los saltos y las piruetas; iyo mismo me he puesto esa corona sobre mi cabeza! Levantad vuestros corazones, hermanos míos, ¡arriba! ¡Más arriba! ¡Y no me olvidéis tampoco las piernas! Levantad también vuestras piernas, vosotros, buenos bailarines y mejor aún: ¡sosteneos incluso sobre la cabeza!...Vosotros hombres superiores, esto es lo peor de vosotros: ninguno habéis aprendido a bailar como hay que bailar- ¡a bailar por encima de vosotros mismos! ¡Qué importa que os hayáis malogrado! (1981, p. 394).

Al final del acto solo queda el olor del tabaco.

\section{Conclusión}

Al hablar de la muerte del Hombre, de la muerte de la Historia lineal y del desdibujamiento de las Ciencias Humanas no estamos hablando de la extinción de la especie humana ni de la extinción de la memoria. Pero sí estamos diciendo que los hombres han vivido desde hace mucho tiempo sin el Hombre, y que no en todas las épocas el tiempo se ha concebido de manera lineal, cronológica. Así mismo, estamos alertando en relación con los dispositivos de poder-saber que manejan las Ciencias Humanas. Es como si los hombres contemporáneos tuviéramos que ponernos en un afuera de esas categorías modernas: afuera del Hombre, afuera de la Historia lineal totalitaria, afuera de la relación sujeto-objeto, yo-otro, lo mismo-lo otro. Desde ese afuera encontraremos a los hombres como seres vivos que estamos en vía de desaparecer gracias a los tenebrosos inventos tecnológicos, genéticos y económicos creados en el interior del Hombre moderno; desde ese afuera encontraremos múltiples modos de existencia, múltiples genealogías, múltiples relatos, muchas maneras de construir historias. Encontraremos, en fin, maneras de experimentar desde un afuera del Hombre; es decir, desde la transformación y los devenires. Así podremos construir subjetivaciones, o modos de existencia que se resistan a los ejercicios de poder-saber propios del Hombre, y hacer de la vida una obra de arte. 


\section{Referencias}

Calderón, P. (2003). Foucault por sí mismo (documental). Francia: Arte France-BFC Productions.

Deleuze, G. (1996). Crítica y clínica. Barcelona: Anagrama.

Deleuze, G. (2005a). Nietzsche et la philosophie. París: PUF.

Deleuze, G. (2005b). La isla desierta y otros textos. España: Pre-textos.

Deleuze, G. \& Guattari, F. (1993). Qué es la filosofía. Barcelona: Anagrama.

Foucault, M. (1968). Las palabras y las cosas. Argentina: Siglo XXI.

Foucault, M. (1999, noviembre). La inquietud del otro. Cuaderno Transhumantes. E. Garavito (Trad.). 43 y ss. Universidad Nacional de Colombia, sede Medellín. Documento oral del Instituto Nacional de la Comunicación visual (INCAV), Francia, transmitido por Radio France el 25 de junio de 1984, con ocasión de la muerte del filósofo.

Foucault, M. (2009). Una lectura de Kant. Introducción a la antropología en sentido pragmático. Argentina: Siglo XXI.

Garavito, E. (1999). Escritos escogidos. Universidad Nacional de Colombia, sede Medellín.

Gutiérrez, R. (2005). Prólogo. En: F. Nietzsche. Ditirambos de Dionisos. Bogotá: El Áncora.

Kant, I. (1978). Crítica de la razón pura. Estética Trascendental. Madrid: Alfaguara.

Kant, I. (2007). Écrits sur le corps et I'esprit. Paris: GF Flammarion.

Levi, P. (2011). Trilogía de Auschwitz. Editorial El Océano.

Nietzsche, F. (1981). Así habló Zaratustra, Libro IV. Madrid: Alianza Editorial.

Nietzsche, F. (1984). Ecce Homo. Madrid: Alianza Editorial.

Nietzsche, F. (2000). La Genealogía de la moral. Madrid: Alianza Editorial.

Nietzsche, F. (2002). Consideraciones intempestivas. Buenos Aires: Alianza. 